\title{
Article \\ Cerebral Arterial Asymmetries in the Neonate: Insight into the Pathogenesis of Stroke
}

\author{
Anica Jansen van Vuuren ${ }^{1}$, Michael Saling ${ }^{1,2, *}$, Sheryle Rogerson ${ }^{3} \mathbb{D}$, Peter Anderson ${ }^{4,5} \mathbb{D}$, Jeanie Cheong ${ }^{3,6}(\mathbb{D}$ \\ and Mark Solms ${ }^{7}$
}

check for updates

Citation: van Vuuren, A.J.; Saling, M.; Rogerson, S.; Anderson, P.; Cheong, J.; Solms, M. Cerebral Arterial Asymmetries in the Neonate: Insight into the Pathogenesis of Stroke. Symmetry 2022, 14, 456. https:// doi.org/10.3390/sym14030456

Academic Editor: Thierry Paillard

Received: 22 December 2021

Accepted: 24 January 2022

Published: 24 February 2022

Publisher's Note: MDPI stays neutral with regard to jurisdictional claims in published maps and institutional affiliations.

Copyright: (C) 2022 by the authors. Licensee MDPI, Basel, Switzerland. This article is an open access article distributed under the terms and conditions of the Creative Commons Attribution (CC BY) license (https:// creativecommons.org/licenses/by/ $4.0 /)$.
1 Melbourne School of Psychological Sciences, University of Melbourne, Melbourne, VIC 3010, Australia; anicajvv@gmail.com

2 Florey Institute of Neurosciences and Mental Health, Royal Parade, Melbourne, VIC 3052, Australia

3 Royal Women's Hospital, Flemington Rd., Melbourne, VIC 3052, Australia; Sheryle.Rogerson@thewomens.org.au (S.R.); Jeanie.Cheong@thewomens.org.au (J.C.)

4 Murdoch Children's Research Institute, Royal Children's Hospital, Flemington Rd., Melbourne, VIC 3052, Australia; peter.anderson@mcri.edu.au

5 Turner Institute for Brain and Mental Health, Monash University, Melbourne, VIC 3800, Australia

6 Clinical Sciences, Murdoch Children's Research Institute, Flemington Road, Melbourne, VIC 3052, Australia

7 Department of Psychology, University of Cape Town, Private Bag, Cape Town 7701, South Africa; mark.solms@uct.ac.za

* Correspondence: mmsaling@unimelb.edu.au

\begin{abstract}
Neonatal and adult strokes are more common in the left than in the right cerebral hemisphere in the middle cerebral arterial territory, and adult extracranial and intracranial vessels are systematically left-dominant. The aim of the research reported here was to determine whether the asymmetric vascular ground plan found in adults was present in healthy term neonates $(\mathrm{n}=97)$. A new transcranial Doppler ultrasonography dual-view scanning protocol, with concurrent B-flow and pulsed wave imaging, acquired multivariate data on the neonatal middle cerebral arterial structure and function. This study documents for the first-time systematic asymmetries in the middle cerebral artery origin and distal trunk of healthy term neonates and identifies commensurately asymmetric hemodynamic vulnerabilities. A systematic leftward arterial dominance was found in the arterial caliber and cortically directed blood flow. The endothelial wall shear stress was also asymmetric across the midline and varied according to vessels' geometry. We conclude that the arterial structure and blood supply in the brain are laterally asymmetric in newborns. Unfavorable shearing forces, which are a by-product of the arterial asymmetries described here, might contribute to a greater risk of cerebrovascular pathology in the left hemisphere.
\end{abstract}

Keywords: middle cerebral artery; diameter; blood flow; asymmetry; stroke; shear stress; neonate

\section{Introduction}

Middle cerebral artery strokes occur more commonly in the left cerebral hemisphere [1,2]. In the mature brain, this leftward predilection has been attributed by some to selective recognition of the clinically obvious sequalae of left hemispheric events [3]. Neurovascular vulnerabilities that might explain a left hemispheric predilection for stroke have also been identified [4].

Adult studies report left-biased asymmetries in the structure and hemodynamics of extracranial and intracranial arteries, namely, the vertebral arteries [5,6], common and internal carotid arteries [7], and middle and anterior cerebral arteries [8]. These reports of larger arterial calibers, higher flow velocities, and higher blood flow volumes on the left are in keeping with the notion of a more resource intensive left hemisphere [9] and create left-right differences in the circulations of each arterial tree.

Hemodynamic processes, such as changes in blood pressure parameters, the speed of the pressure wave propagation, and resulting shearing forces on the arterial endothelium, 
play important roles in the development of vascular disease [10]. The distribution of atherosclerosis in the vascular system is not uniform and plaque severity and composition also varies according to location [11]. Reports of higher left-than-right intima-media wall thickness [12] and plaque incidence, thickness, and instability [3] in the carotid arteries suggest a lateralized vulnerability to cerebrovascular disease in adults.

A left hemisphere predilection for cerebrovascular pathology, such as periventricular hemorrhage [13], neonatal stroke [14], and cerebral palsy [15], has also been reported in neonates. Approximately $70 \%$ to $80 \%$ of neonatal ischemic strokes occur in the middle cerebral arterial field, and they are left-sided in 53\% to $75 \%$ of cases [16]. This begs a key question: is the ground plan of adult arterial asymmetries and corresponding vulnerability to pathology discernible in neonates? There is only one study, to our knowledge, that aimed to investigate the significance of left-right differences in the blood flow velocity to neonatal stroke, but only 20 normal control cases were reported, without data on arterial diameter, flow volume, or shear stress [17].

Ultrasonography of neonatal cerebral arteries is common in routine clinical practice and largely proceeds on the assumption of trans-midline symmetry. The resolution of existing methodologies has not been extended to detect the existence of structurofunctional asymmetries]. In previously used Doppler technologies, "bleeding", blooming artefact, and the influence of gain settings are recognized sources of error, particularly in relation to diametric measurement. This is problematic, since conclusions about regional cerebral blood flow cannot be drawn from velocity measurements [18], primarily because the volume flow $(\mathrm{Q})$ in a vessel is related to the velocity $(\mathrm{V})$ as well as the vessel's radius $(\mathrm{R})$ according to the equation $Q=V \pi R^{2}$. Similarly, the calculation of the wall shear stress requires a diametric measurement according to the equation $\tau=4 \mu\left(V / \pi D^{3}\right)$. B-flow imaging is a recently introduced non-Doppler technology which effectively bypasses these difficulties [19]. A dual-view imaging protocol using concurrent pulsed wave and B-flow Doppler transcranial ultrasonography addresses these shortcomings and paves the way for investigating the aims of the research reported here, namely, to investigate neonatal arterial asymmetry and corresponding cerebrovascular vulnerabilities.

We focused on the trunk of the middle cerebral artery as a major and accessible conduit to the lateral neocortical territory. We hypothesized that the diameter, hemodynamics, and shear stress are all inherently asymmetric in the direction of larger arterial calibers, higher blood flow volumes, and unfavorable shear stress on the left in the majority of healthy term neonates.

\section{Materials and Methods}

\subsection{Search Strategy and Selection Criteria}

Transcranial Doppler ultrasonography was performed on 106 healthy term neonates. Neonates with a gestational age greater than 37 weeks were recruited consecutively between March 2017 and November 2017 from the postnatal wards of the Royal Women's Hospital and Frances Perry House in Melbourne, Australia. A non-randomized participant sampling approach accompanied by comprehensive exclusion criteria (see below) was adopted. Six participants were excluded from the final analysis because aberrant middle cerebral arterial branching patterns precluded left-right comparisons of arterial geometry and hemodynamics. An additional three participants were excluded for poor image quality because of excessive neonatal movement, excessive hair, and or small cranial windows.

\subsection{Neonatal Exclusion Criteria}

Infants with significant perinatal complications were excluded (for example, postnatal resuscitation and/or admission to the neonatal intensive and special care nursery). Neonates with an intracranial pathology, substance exposure, or metabolic, genetic, and/or cardiovascular disorders were excluded. All infants enrolled in the study were healthy and had no dysmorphic features during the neonatal predischarge check. 


\subsection{Maternal Exclusion Criteria}

Exclusion criteria included diagnoses of autoimmune disorders, pre-gestational diabetes mellitus, gestational diabetes, cardiac disease, drug and substance use, instances of suspected or detected fetal abnormality prior to delivery, chronic or persistent hypertension (>140/90), infections (including active genital herpes, syphilis, and HIV+), pre-eclampsia, and neurological and mental health conditions. Non-English-speaking parents were excluded from the study to ensure effective communication and understanding between the parent and investigators.

All scanning took place at the Royal Women's Hospital, Melbourne, Australia. Ethical approval was granted by the Royal Women's Hospital Human Research Ethics Committee and written informed consent was obtained from one or both parents.

\subsection{Procedure}

Transcranial ultrasonography and Doppler assessment took place at a postnatal age of 1 to 7 days. Scans did not reflect acute hemodynamic changes known to occur in the first $12 \mathrm{~h}$ of life [20]. Standard medical procedure was followed prior to the analysis. All infants underwent $10 \mathrm{~min}$ of supine rest on a clean cot in a standardized sound proofed ultrasound room with no auditory or visual distractions. The room had constant illumination and comfortable room temperature. Neonates were swaddled and fed prior to the scanning session. Parents were positioned at the head of the cot, behind the investigator so as not to distract the infant. If the neonate began to cry, the neonate was soothed before resuming the procedure.

Transcranial Doppler cerebrovascular imaging was performed using the portable General Electric EPIQ 9 ultrasound unit (GE Healthcare, Wauwatosa, WI, USA). A C3$10-\mathrm{D}$ convex probe $(2-11 \mathrm{MHz})$ with an insonation angle close to $0^{\circ}$ was used. Further settings included a small sample volume of $2 \mathrm{~mm}$ with a velocity wall filter of $80-100 \mathrm{~Hz}$ to eliminate noise caused by vessel wall movement.

Using a trans-temporal approach, the middle cerebral artery trunk was located by placing the transducer on the left temporal bone, below the zygomatic arch. Screening for previously undetected pathology and identification of the middle cerebral artery was performed with two-dimensional B mode gray-scale imaging and color flow imaging through the temporal window. B-flow imaging was activated, and the probe was moved so as to optimize the visualization of the origin of the middle cerebral artery trunk (approximately $2 \mathrm{~mm}$ from internal carotid artery terminus). At this distance, the vessel has a uniform diameter and required minimal angle correction. In any necessary instance, an angle of correction was performed if the angle of incidence was greater than $15^{\circ}$ to ensure the transducer remained parallel to the vector of blood flow and accurate measures were obtained. Dual-view imaging was then initiated to replicate the image into two identical left and right images. The left image was selected, pulsed wave Doppler was activated, and several hemodynamic measurements were recorded at the arterial site. B-flow and pulsed wave frequencies used were $6.0 \mathrm{MHz}$ and $4.2 \mathrm{MHz}$ respectively. Three distinct pulsed wave spectral tracings containing three consecutive cardiac cycles were recorded. Peak systolic velocity (PSV), end-diastolic velocity (EDV), time averaged maximum velocity (TA $\mathrm{AAX}_{\mathrm{MA}}$, time averaged mean velocity ( $\left.T A_{M E A N}\right)$, and heart rate measures were obtained. An on-site arterial diameter was taken from the corresponding right B-Flow image in the exact location hemodynamic measures were sourced.

The distal portion of the middle cerebral artery trunk (distal to the origins of the lenticulostriate arteries) approximately $2 \mathrm{~mm}$ from the middle cerebral artery bifurcation/trifurcation was located, and hemodynamic and diameter measures were repeated. The procedure was then repeated on the contralateral Mo and $\mathrm{M}_{\mathrm{DT}}$ sites. The sequence of data collection from the left and right middle cerebral arteries was randomized.

As a proof of concept for the new scanning protocol, we also imaged the very fine lenticulostriate branches of the middle cerebral trunk to a high degree of resolution. Lenticulostriate artery sampling in the study was sparse, largely because these vessels are difficult 
to image and of a small caliber. The fact that lenticulostriate arteries were imaged to the point of supporting reliable measurement attests to the resolution of the innovations that were introduced to accomplish this.

The lenticulostriate arteries of the left and right cerebral hemisphere were approached by placing the same C3-10 transducer in the mid-sagittal plane of the anterior fontanelle. The transducer was fanned into the left cerebral hemisphere. Screening and identification of the lenticulostriate arteries was performed with two-dimensional B mode gray-scale imaging and color flow imaging. B-flow imaging was activated and two lenticulostriate arteries in each cerebral hemisphere were chosen for further scanning based on the clarity of the image and orientation of the vessel (that is, the two arteries on each side that were most oriented in the vertical plane). The probe was moved so as to optimize the visualization of one of the selected vessels. B-flow and pulsed wave Doppler was utilized in dual-view imaging to record structural and hemodynamic measures of the lenticulostriate artery. The procedure was then repeated for the second unilateral and two contralateral lenticulostriate arteries in a randomized order.

All images were stored on optical disc for off-line analysis using SYNAPSE (PACS) 64-bit imaging software. All hemodynamic measures were averaged across three homogenous consecutive cardiac cycles for each arterial site. Further investigation of arterial diameter was performed offline with RadiAnt DICOM viewer (64-bit) imaging software (version 4.2.1). The mean lumen diameter of each arterial site was determined by averaging three independent measurements taken at the same location as on-line analyses. Parameters were also averaged across the ipsilateral origin and distal trunk of middle cerebral artery $\left(\mathrm{MCA}_{\mathrm{MEAN}}\right)$. Assessment of inter-rater reliability was performed by SR, an experienced sonographer, on $10 \%$ of participants randomly selected from the sample throughout the data collection period. Cronbach's alpha showed a high internal consistency of 0.963 .

At each site, the following hemodynamic indices were calculated with the following formulae. Mean velocity $\left(V_{M E A N}\right)$ :

$$
V_{M E A N}=\frac{P S V+E D V}{2}
$$

Resistive index (RI) computed according to the method of Pourcelot (1982):

$$
R I=\frac{P S V-E D V}{P S V}
$$

Pulsatility index (PI) computed according to the method of Gosling and King (1988):

$$
P I=\frac{P S V-E D V}{V_{M E A N}}
$$

Shear stress $\left(\tau\right.$; dyne $\left./ \mathrm{cm}^{2}\right)$ :

$$
\tau=4 \cdot \mu \cdot \frac{V}{\pi \cdot D^{3}}
$$

where $V$ equals the flow velocity, $\mu$ equals the viscosity of flow, and $D$ equals the arterial diameter. No data was available concerning blood viscosity in the neonates, so an average neonatal hematocrit-adjusted (0-45) blood viscosity, adjusted at high shear rates of $4.22 \mathrm{mPa}$.s, was assumed [21], as there is no reason to suspect intraindividual viscosity differences or systematic differences between left- and right-dominant neonates.

Volume flow $(Q)$ :

$$
Q=P S V \times\left(D^{2}\left(\frac{\pi}{4}\right)\right)
$$

Peak systolic velocity was used as a variable in the calculation of volume flow because it is sensitive to left-right differences in the neonate [22], is mediated by arterial structure [23], and reflects cerebral blood flow [24], the definition of which is the primary aim of this work. Average measures (such as $\mathrm{TA}_{\mathrm{MEAN}}$ ) inevitably conflate peak systolic velocity 
with end-diastolic velocity. While this might be useful in particular clinical applications, end-diastolic velocities show less left-right differentiation [25].

Arterial diameter was used as a grouping variable for the sample. Interhemispheric diameter dominance was expressed in the form of a left-right laterality index and calculated with the formula:

$$
\text { Laterality index }=\frac{L-R}{L+R}
$$

where $R$ equals the right arterial measure and $L$ the left arterial measure. A positive value indicated left arterial dominance, whereas a negative value indicated right arterial dominance. A score of 0 represents the absence of a structural dominance. A LI was calculated for each arterial site as well as the cerebral artery average between the middle cerebral origin and distal trunk (MCA $\left.\mathrm{MEAN}_{\mathrm{N}}\right)$.

\subsection{Statistical Analyses}

Data were analyzed using IBM SPSS Statistics (version 23) software. Each hemodynamic measure of the middle cerebral arteries was analyzed using a mixed-design ANOVA. Neonates with no structural arterial dominance were removed from the analysis. For each analysis, the within-subjects factor was the respective arterial parameter (of the left and right paired arteries) and the between-subjects factor was the structural dominance (left-dominant or right-dominant). One-tailed paired t-tests compared lateral differences in geometric groups in instances of significant interactions. One-tailed independent $t$-tests also compared sex differences in participant demographics and hemodynamics parameters at each site of measurement. Tests of normality and homoscedasticity (namely Levene's test of equality of variance and Shapiro-Wilk tests) were run on each dataset. If the assumption of normality was not upheld, a non-parametric Mann-Whitney $U$ test was run instead.

For brevity, results for TA $\mathrm{AAX}_{\mathrm{MA}}$ and TAMEAN are omitted as they are collinear with PSV $(r>0.90)$ and $\mathrm{V}_{\text {MEAN }}(r>0.90)$, respectively, as described below, but might not be as precise as PSV in defining lateral difference (see above).

Internal consistency was calculated using Cronbach's alpha in $10 \%$ of cases. Cohen's rule of thumb for effect size interpretations was used for between-group comparisons: $d=0.10$ (small effect), $d=0.30$ (medium effect), and $d=0.50$ (large effect). The significance of the analyses was determined with a $95 \%$ confidence level at $p<0.05$.

\section{Results}

The geometric and hemodynamic properties of the middle cerebral artery origin and termination of its trunk were recorded in 97 healthy full-term neonates. The final sample included 59 males and 38 females born via normal vaginal delivery or caesarean section (Table 1). The gestational age at birth of the sample ranged from 36 to 41 weeks, and birth weights ranged from $2200 \mathrm{~g}$ to $4930 \mathrm{~g}$. The postnatal age at the time of scanning was 12 to $174 \mathrm{~h}(M=47.71 \mathrm{~h} ; S D=28.58 ;$ Median $=41 \mathrm{~h} ;$ Range $=162 \mathrm{~h})$. Mean Apgar scores were 8.30 at $1 \mathrm{~min}(S D=1.38)$ and 8.92 at $5 \mathrm{~min}(S D=0.32)$. The sample spent an average of $68 \mathrm{~h}$ in hospital. There were no significant sex differences in the birth weight, postnatal scanning age, or gestational age.

As an example of dual views of B-mode and pulsed wave Doppler ultrasound imaging, Figure 1 illustrates the diameter and hemodynamic variability of the left and right middle cerebral arteries. As a proof of concept, we also imaged the very fine lenticulostriate branches of the middle cerebral trunk to a high degree of resolution. Example images are included in Figure 1. Demographic information on the neonates according to their averaged middle cerebral geometric asymmetry (left-dominant or right-dominant) is presented in Table 1. 
Table 1. Neonatal characteristics as a function of geometric arterial asymmetry.

\begin{tabular}{|c|c|c|c|c|}
\hline & Left-Dominant & Right-Dominant & No Dominance & Total \\
\hline & $M(S D)$ & $M(S D)$ & $M(S D)$ & $M(S D)$ \\
\hline$N^{\mathrm{a}}$ & 57 & 34 & 6 & 97 \\
\hline \multicolumn{5}{|l|}{$\operatorname{Sex}(\%)$} \\
\hline Male & 61.4 & 64.7 & 66.7 & 62.9 \\
\hline Female & 39.6 & 35.3 & 33.3 & 37.1 \\
\hline Gestational age at birth (wk) & $39.07(1.45)$ & $38.76(1.46)$ & $39.00(1.67)$ & $38.99(1.45)$ \\
\hline Age at scan (hrs) & 48.44 (32.17) & $48.88(23.94)$ & $38.00(11.22)$ & $47.71(28.58)$ \\
\hline Birth weight (g) & $3418.51(539.94)$ & $3525.15(621.10)$ & $3428.00(470.34)$ & $3460.76(560.37)$ \\
\hline $\mathrm{AS}^{1 \mathrm{~min}}$ & $8.40(1.31)$ & $8.18(1.49)$ & $8.5(1.22)$ & $8.30(1.38)$ \\
\hline $\mathrm{AS}^{5 \mathrm{~min}}$ & $8.91(0.39)$ & $8.97(0.17)$ & $9(0.00)$ & $8.92(0.32)$ \\
\hline Heart rate (bt/min) & $113.62(14.64)$ & $111.82(13.79)$ & $114.58(17.07)$ & $113.87(13.89)$ \\
\hline
\end{tabular}

Note: $\mathrm{AS}^{1 \mathrm{~min}}=$ Apgar score at $1 \mathrm{~min} ; \mathrm{AS}^{5 \mathrm{~min}}=$ Apgar score at $5 \mathrm{~min}{ }^{\mathrm{a}}=$ number according to geometric dominance averaged across middle cerebral origin and distal trunk.

Left Cerebral Hemisphere

A. Middle cerebral artery origin:

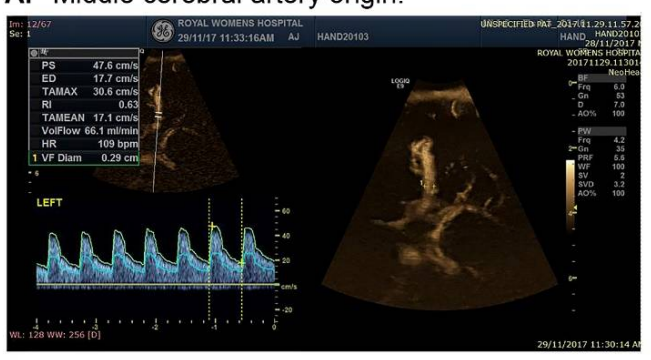

B. Middle cerebral artery distal trunk:
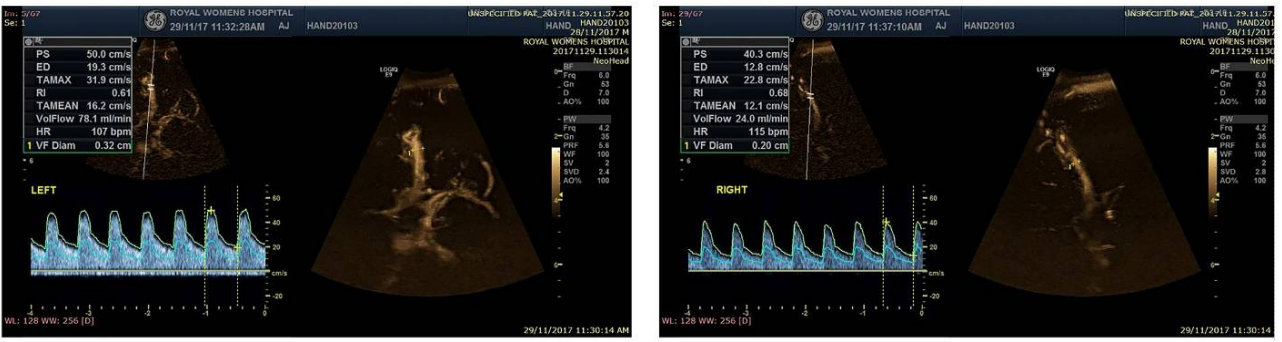

C. Lenticulostriate artery:
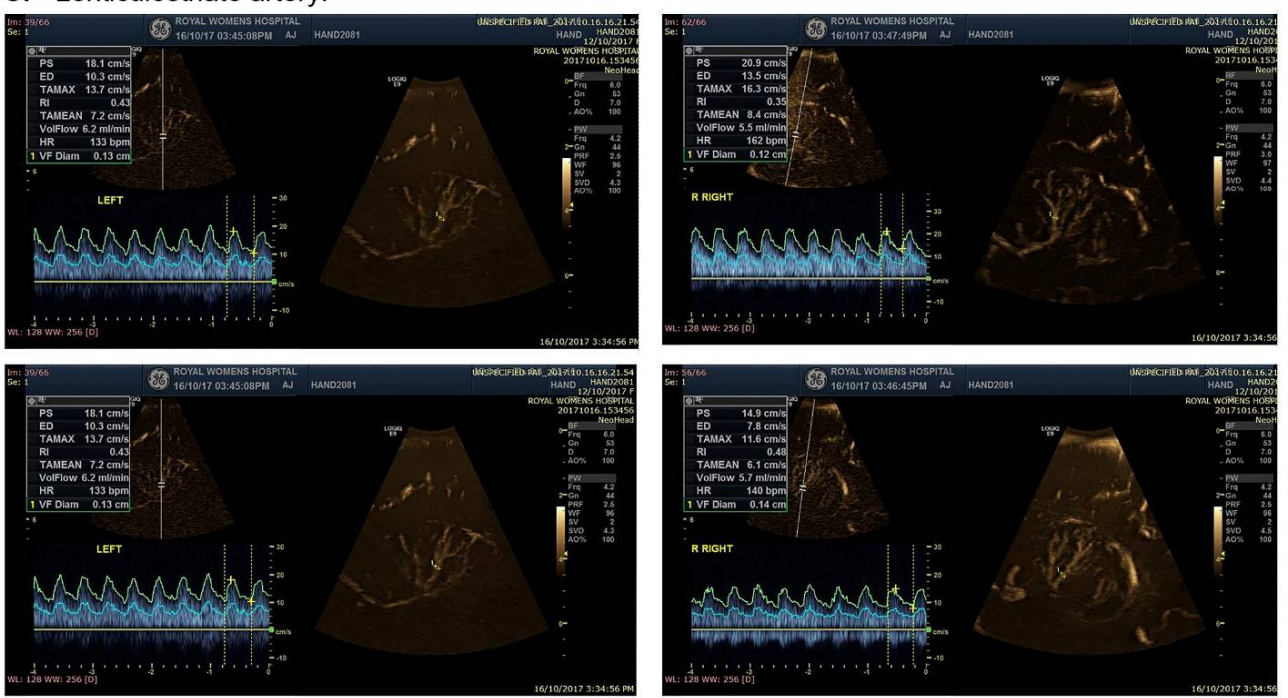

Figure 1. An example of dual-view B-flow and pulsed wave imaging in a left-dominant infant. The brown-scale arterial images and the blue-scale cardiac cycles for measurement of velocities are shown. 
Panels (A): origin of the left and right middle cerebral arteries. The diameter on the left is $2.9 \mathrm{~mm}$ and the diameter on the right is $2.1 \mathrm{~mm}$; the difference is visible on inspection of the brown-scale images. Peak systolic velocity on the left (PS in the quantitative panel) is $47.6 \mathrm{~cm} / \mathrm{s}$ and $40.3 \mathrm{~cm} / \mathrm{s}$ on the right. The end-diastolic velocity (ED in the quantitative panel) is $17.7 \mathrm{~cm} / \mathrm{s}$ on the left and $11.2 \mathrm{~cm} / \mathrm{s}$ on the right. Panels (B): distal segment of the trunk of the left and right middle cerebral arteries. The diameter on the left is $3.2 \mathrm{~mm}$ and $2.0 \mathrm{~mm}$ on the right, and the difference is again visible on inspection of the brown-scale images. Peak systolic velocity (PS) is $50 \mathrm{~cm} / \mathrm{s}$ on the left and $40.3 \mathrm{~cm} / \mathrm{s}$ on the right. End-diastolic velocity (ED) is $19.3 \mathrm{~cm} / \mathrm{s}$ on the left and $12.8 \mathrm{~cm} / \mathrm{s}$ on the right. Panels (C): the lenticulostriate arteries are shown largely as a proof of the concept that very small caliber arteries in the neonatal brain can be visualized and that structurofunctional measurements can be obtained. The arteries selected for measurement can be identified by the white dotted lines in the brown-scale images.

\subsection{Sex Differences}

No significant sex differences were found in the arterial diameter; peak systolic, end-diastolic, and mean velocity; and resistance or pulsatility indices. A significant sex difference was found in the blood flow volume in the left middle cerebral origin. Overall, males had higher left-sided blood flow volumes $(M=210.04 \mathrm{~mL} / \mathrm{min}$; $S D=75.05)$ than females $(M=189.87 \mathrm{~mm} ; S D=80.50)$ at this arterial site $(p=0.041)$. Shearing forces at each corresponding arterial site were comparable between males and females apart from the shear stress in the distal trunk of the right middle cerebral artery. Females had a higher right-sided wall shear stress $\left(M=595.99\right.$ dyne $\left./ \mathrm{cm}^{2} ; S D=208.90\right)$ than males $\left(M=504.71\right.$ dyne $\left./ \mathrm{cm}^{2} ; S D=137.61\right)$ at the distal trunk $(p=0.034)$.

\subsection{Structural Differences}

Left-right asymmetries in the arterial diameter were found at each arterial site $(p<0.001$; Table 2). Of the 97 participating neonates, a left geometric dominance was exhibited in $52(54 \%)$ at the middle cerebral origin and $60(62 \%)$ at the middle cerebral distal trunk. When averaged across the arteries, with no consideration of individual dominance, a significant leftward structural difference was evident only at the middle cerebral distal trunk $(\mathrm{t}(96)=1.989, p=0.050, d=0.239)$. A small proportion of participants showed no left-right differences in the arterial diameter at the origin (8\%) and distal trunk (4\%). Laterality indices of structure at the middle cerebral artery proximal segment were associated with asymmetries at the distal segment $(r=0.741 ; p<0.001)$.

Analyses described in this paper have not been undertaken in previous work. Rather, left-right comparisons classically are made on the basis of average values across the entire sample and with measurements taken at a single site, namely the origin of the middle cerebral artery. The findings reported in the "Averaged" column of Table 2 show that this approach hides or reduces the probability of the systematic individual lateral dominance reported here.

\subsection{Structurofunctional Differences}

Considerable geometric and hemodynamic asymmetries existed in the origin and distal trunk of the middle cerebral artery. In participants with a leftward dominance in the arterial geometry, peak blood flow velocities were higher on the left side at both sites of the middle cerebral artery. A leftward bias in the average flow velocity was found at the origin, and higher blood flow volumes were also found in the larger left origin and distal trunk of this group. No lateral differences in the end-diastolic velocity were found at either site.

Across both middle cerebral arterial sites, no lateral differences in the peak systolic, end-diastolic of average blood flow velocity were found in neonates with larger arteries on the right side (Tables 3 and 4; Figure 2). Converse to neonates with a leftward dominance in the geometry, a right-sided asymmetry in the overall blood flow volume was found at the origin and distal trunk of neonates with larger arteries in the right hemisphere. 
Table 2. Intra-individual left-right diametric differences as a function of inter-individual differences in the direction of arterial asymmetry.

\begin{tabular}{|c|c|c|c|c|c|}
\hline & & Left-Dominant & Right-Dominant & No Dominance & Averaged $^{a}$ \\
\hline Artery & Side & $M(S D)$ & $M(S D)$ & $M(S D)$ & $M(S D)$ \\
\hline \multirow[t]{4}{*}{$\mathrm{MCA}_{\mathrm{O}}(\mathrm{mm})$} & $n$ & 52 & 37 & 8 & 97 \\
\hline & $L$ & $2.32(0.35)$ & $1.95(0.25)$ & $2.01(0.17)$ & $2.13(0.35)$ \\
\hline & $R$ & $1.91(0.23)$ & $2.39(0.43)$ & $2.01(0.17)$ & $2.11(0.39)$ \\
\hline & $p$ & 0.000 & 0.000 & - & 0.412 \\
\hline \multirow[t]{4}{*}{$\mathrm{MCA}_{\mathrm{DT}}(\mathrm{mm})$} & $n$ & 60 & 33 & 4 & 97 \\
\hline & $L$ & $2.14(0.35)$ & $1.87(0.27)$ & $2.03(0.20)$ & $2.04(0.34)$ \\
\hline & $R$ & $1.81(0.22)$ & $2.22(0.34)$ & $2.03(0.20)$ & $1.96(0.33)$ \\
\hline & $p$ & 0.000 & 0.000 & - & 0.050 * \\
\hline \multirow{4}{*}{$\operatorname{MCA}_{\text {MEAN }}(\mathrm{mm})$} & $n$ & 57 & 34 & 6 & 97 \\
\hline & $L$ & $2.14(0.35)$ & $1.86(0.27)$ & $2.03(0.16)$ & $2.09(0.33)$ \\
\hline & $R$ & $1.81(0.22)$ & $2.22(0.35)$ & $2.03(0.16)$ & $2.03(0.34)$ \\
\hline & $p$ & 0.000 & 0.000 & - & 0.158 \\
\hline
\end{tabular}

Note: $p<0.05 ; \mathrm{MCA}_{\mathrm{O}}=$ middle cerebral artery origin; $\mathrm{MCA}_{\mathrm{DT}}=$ middle cerebral artery distal trunk; $\mathrm{MCA}_{\text {MEAN }}=$ middle cerebral artery averaged across origin and distal trunk measures; ${ }^{\mathrm{a}}=$ averaged across the sample with no consideration of individual differences in arterial asymmetry.

Table 3. Comparisons of hemodynamic parameters between left and arterial sites according to geometric dominance.

\begin{tabular}{|c|c|c|c|c|c|c|c|c|c|c|}
\hline \multirow[b]{2}{*}{ Artery } & \multirow[b]{2}{*}{ Dominance } & \multirow[b]{2}{*}{ Parameter } & \multicolumn{2}{|c|}{ Left Hemisphere } & \multicolumn{2}{|c|}{ Right Hemisphere } & \multirow[b]{2}{*}{$\mathbf{t}$} & \multirow[b]{2}{*}{ df } & \multirow[b]{2}{*}{$p$} & \multirow[b]{2}{*}{ d } \\
\hline & & & $M$ & $S D$ & $M$ & $S D$ & & & & \\
\hline \multirow[t]{16}{*}{$\mathrm{MCA}_{\mathrm{O}}$} & \multirow[t]{8}{*}{ Left } & $\begin{array}{l}\text { PSV } \\
(\mathrm{cm} / \mathrm{s})\end{array}$ & 54.00 & 10.23 & 51.24 & 11.28 & 2.307 & 51 & $0.013 *$ & 0.331 \\
\hline & & $\begin{array}{l}\text { EDV } \\
(\mathrm{cm} / \mathrm{s})\end{array}$ & 18.91 & 4.42 & 18.25 & 5.45 & 1.140 & 51 & 0.130 & 0.154 \\
\hline & & $\begin{array}{l}\mathrm{V}_{\text {MEAN }} \\
(\mathrm{cm} / \mathrm{s})\end{array}$ & 30.58 & 5.77 & 29.25 & 6.92 & 1.866 & 51 & $0.033 *$ & 0.257 \\
\hline & & RI & 0.65 & 0.07 & 0.64 & 0.07 & 0.250 & 51 & 0.402 & 0.163 \\
\hline & & PI & 0.96 & 0.14 & 0.96 & 0.15 & 0.195 & 51 & 0.423 & 0.000 \\
\hline & & $\begin{array}{l}\mathrm{Q} \\
(\mathrm{mL} / \mathrm{min})\end{array}$ & 232.52 & 83.44 & 149.98 & 41.15 & 7.509 & 51 & $0.000 *$ & 1.048 \\
\hline & & $\begin{array}{l}\text { WSS } \\
\left(\text { dyne }_{\text {sysm }} / \mathrm{cm}^{2}\right)\end{array}$ & 80.36 & 18.77 & 91.32 & 22.39 & -5.118 & 51 & $0.000 *$ & -0.727 \\
\hline & & $\begin{array}{l}\text { WSS DIAS } \\
\left(\text { dyne } / \mathrm{cm}^{2}\right)\end{array}$ & 2.80 & 0.68 & 3.24 & 1.00 & -2.022 & 51 & $0.000 *$ & -0.683 \\
\hline & \multirow[t]{8}{*}{ Right } & $\begin{array}{l}\text { PSV } \\
(\mathrm{cm} / \mathrm{s})\end{array}$ & 56.04 & 14.85 & 57.67 & 14.62 & -0.945 & 36 & 0.176 & 0.155 \\
\hline & & $\begin{array}{l}\text { EDV } \\
(\mathrm{cm} / \mathrm{s})\end{array}$ & 18.63 & 6.97 & 19.53 & 6.28 & -1.253 & 36 & 0.109 & 0.230 \\
\hline & & $\begin{array}{l}V_{\text {MEAN }} \\
(\mathrm{cm} / \mathrm{s})\end{array}$ & 31.10 & 9.17 & 32.24 & 8.73 & -1.167 & 36 & 0.125 & 0.191 \\
\hline & & RI & 0.67 & 0.07 & 0.66 & 0.06 & 0.857 & 36 & 0.199 & 0.187 \\
\hline & & PI & 1.01 & 0.15 & 0.99 & 0.13 & 0.937 & 36 & 0.178 & 0.173 \\
\hline & & $\begin{array}{l}\mathrm{Q} \\
(\mathrm{mL} / \mathrm{min})\end{array}$ & 167.15 & 52.67 & 266.11 & 123.28 & -5.630 & 36 & 0.000 * & 0.926 \\
\hline & & $\begin{array}{l}W_{S S} \text { SYS } \\
\left(\text { dyne } / \mathrm{cm}^{2}\right)\end{array}$ & 99.51 & 32.68 & 84.14 & 27.73 & 20.270 & 36 & $0.001 *$ & 0.572 \\
\hline & & $\begin{array}{l}\text { WSS DIAS } \\
\left(\text { dyne } / \mathrm{cm}^{2}\right)\end{array}$ & 3.32 & 1.46 & 2.87 & 1.19 & 0.664 & 36 & $0.007^{*}$ & 0.432 \\
\hline \multirow[t]{3}{*}{$\mathrm{MCA}_{\mathrm{DT}}$} & \multirow[t]{3}{*}{ Left } & $\begin{array}{l}\text { PSV } \\
(\mathrm{cm} / \mathrm{s})\end{array}$ & 53.26 & 12.72 & 51.03 & 14.23 & 1.947 & 59 & $0.028^{*}$ & 0.251 \\
\hline & & $\begin{array}{l}\mathrm{EDV} \\
(\mathrm{cm} / \mathrm{s})\end{array}$ & 18.28 & 5.53 & 18.14 & 6.45 & 0.245 & 59 & 0.407 & 0.032 \\
\hline & & $\begin{array}{l}V_{\text {MEAN }} \\
(\mathrm{cm} / \mathrm{s})\end{array}$ & 29.94 & 7.52 & 29.10 & 8.65 & 1.173 & 59 & 0.123 & 0.152 \\
\hline
\end{tabular}


Table 3. Cont.

\begin{tabular}{|c|c|c|c|c|c|c|c|c|c|c|}
\hline \multirow[b]{2}{*}{ Artery } & \multirow[b]{2}{*}{ Dominance } & \multirow[b]{2}{*}{ Parameter } & \multicolumn{2}{|c|}{ Left Hemisphere } & \multicolumn{2}{|c|}{ Right Hemisphere } & \multirow[b]{2}{*}{$\mathbf{t}$} & \multirow[b]{2}{*}{ df } & \multirow[b]{2}{*}{$p$} & \multirow[b]{2}{*}{ d } \\
\hline & & & $M$ & $S D$ & $M$ & $S D$ & & & & \\
\hline & & RI & 0.66 & 0.06 & 0.65 & 0.07 & 1.773 & 59 & $0.041 *$ & 0.193 \\
\hline & & PI & 0.99 & 0.14 & 0.96 & 0.15 & 1.726 & 59 & $0.045^{*}$ & 0.260 \\
\hline & & $\begin{array}{l}\mathrm{Q} \\
(\mathrm{mL} / \mathrm{min})\end{array}$ & 193.68 & 71.06 & 130.20 & 37.92 & 8.093 & 59 & $0.000 *$ & 1.045 \\
\hline & & $\begin{array}{l}W_{\text {SSS }} \\
\left(\text { dyne } / \mathrm{cm}^{2}\right)\end{array}$ & 86.69 & 26.81 & 97.56 & 33.08 & -4.597 & 59 & $0.000 *$ & -0.628 \\
\hline & & $\begin{array}{l}\text { WSS DIAS } \\
\left(\text { dyne } / \mathrm{cm}^{2}\right)\end{array}$ & 2.97 & 1.06 & 3.48 & 1.36 & -4.574 & 59 & $0.000 *$ & -0.625 \\
\hline & Right & $\begin{array}{l}\text { PSV } \\
(\mathrm{cm} / \mathrm{s})\end{array}$ & 53.90 & 12.42 & 54.73 & 11.86 & -0.628 & 32 & 0.267 & 0.109 \\
\hline & & $\begin{array}{l}\text { EDV } \\
(\mathrm{cm} / \mathrm{s})\end{array}$ & 17.06 & 5.52 & 17.56 & 4.98 & -0.735 & 32 & 0.233 & 0.127 \\
\hline & & $\begin{array}{l}V_{\text {MEAN }} \\
(\mathrm{cm} / \mathrm{s})\end{array}$ & 29.58 & 7.71 & 29.95 & 6.70 & -0.422 & 32 & 0.338 & 0.073 \\
\hline & & RI & 0.68 & 0.06 & 0.68 & 0.06 & 0.629 & 32 & 0.267 & 0.000 \\
\hline & & PI & 1.03 & 0.15 & 1.03 & 0.15 & 0.588 & 32 & 0.267 & 0.000 \\
\hline & & $\begin{array}{l}\mathrm{Q} \\
(\mathrm{mL} / \mathrm{min})\end{array}$ & 148.46 & 50.63 & 217.59 & 88.24 & -6.771 & 32 & 0.000 * & 1.178 \\
\hline & & $\begin{array}{l}W_{S S} \text { SYS } \\
\left(\text { dyne }_{\mathrm{cm}^{2}}\right)\end{array}$ & 100.26 & 30.39 & 84.80 & 20.63 & 4.705 & 32 & $0.000 *$ & 0.940 \\
\hline & & $\begin{array}{l}\text { WSS DIAS } \\
\left(\text { dyne } / \mathrm{cm}^{2}\right)\end{array}$ & 3.16 & 1.22 & 2.71 & 0.80 & 3.081 & 32 & $0.002 *$ & 0.602 \\
\hline
\end{tabular}

Note: $p<0.05 ; \mathrm{MCAO}=$ middle cerebral artery origin; MCADT = middle cerebral artery distal trunk; PSV = peak systolic velocity; $\mathrm{EDV}$ = end diastolic velocity; VMEAN = mean velocity; RI = resistance index; $\mathrm{PI}$ = pulsatility index; $\mathrm{Q}=$ blood flow volume; WSSSYS = systolic wall shear stress; WSSDIAS = diastolic wall shear stress; * = significant $p$ values.

Table 4. Effects of geometric dominance on hemodynamic parameters of arterial sites.

\begin{tabular}{|c|c|c|c|c|c|c|c|c|c|}
\hline & \multirow[b]{2}{*}{ Source } & \multicolumn{4}{|c|}{ Middle Cerebral Origin } & \multicolumn{4}{|c|}{ Middle Cerebral Distal Trunk } \\
\hline & & df & $\mathbf{F}$ & $p$ & $\eta p^{2}$ & df & $\mathbf{F}$ & $p$ & $\eta p^{2}$ \\
\hline \multirow[t]{3}{*}{ PSV } & PSV & 1 & 0.266 & 0.607 & 0.003 & 1 & 0.584 & 0.447 & 0.006 \\
\hline & $\begin{array}{l}\text { Geometric } \\
\text { dominance }\end{array}$ & 1 & 2.902 & 0.092 & 0.032 & 1 & 0.663 & 0.418 & 0.007 \\
\hline & $\begin{array}{l}\mathrm{PSV}^{*} \text { Geometric } \\
\text { dominance }\end{array}$ & 1 & 4.621 & $0.034^{*}$ & 0.050 & 1 & 2.795 & 0.098 & 0.030 \\
\hline \multirow[t]{3}{*}{ EDV } & EDV & 1 & 0.055 & 0.815 & 0.001 & 1 & 0.154 & 0.696 & 0.002 \\
\hline & $\begin{array}{l}\text { Geometric } \\
\text { dominance }\end{array}$ & 1 & 0.184 & 0.669 & 0.002 & 1 & 0.613 & 0.436 & 0.007 \\
\hline & $\begin{array}{l}\mathrm{EDV}^{*} \text { Geometric } \\
\text { dominance }\end{array}$ & 1 & 2.877 & 0.093 & 0.032 & 1 & 0.484 & 0.488 & 0.005 \\
\hline \multirow[t]{3}{*}{$\mathrm{V}_{\text {MEAN }}$} & $\mathrm{V}_{\text {MEAN }}$ & 1 & 0.028 & 0.868 & 0.000 & 1 & 0.162 & 0.689 & 0.002 \\
\hline & $\begin{array}{l}\text { Geometric } \\
\text { dominance }\end{array}$ & 1 & 1.345 & 0.249 & 0.015 & 1 & 0.023 & 0.879 & 0.000 \\
\hline & $\begin{array}{l}\mathrm{V}_{\text {MEAN }}{ }^{*} \text { Geometric } \\
\text { dominance }\end{array}$ & 1 & 4.382 & $0.039 *$ & 0.048 & 1 & 1.079 & 0.302 & 0.012 \\
\hline \multirow[t]{3}{*}{ RI } & RI & 1 & 0.580 & 0.448 & 0.007 & 1 & 2.441 & 0.122 & 0.026 \\
\hline & $\begin{array}{l}\text { Geometric } \\
\text { dominance }\end{array}$ & 1 & 2.390 & 0.126 & 0.027 & 1 & 4.779 & $0.031 *$ & 0.050 \\
\hline & $\begin{array}{l}\mathrm{RI}^{*} \text { Geometric } \\
\text { dominance }\end{array}$ & 1 & 0.175 & 0.667 & 0.002 & 1 & 0.331 & 0.566 & 0.004 \\
\hline \multirow[t]{3}{*}{ PI } & PI & 1 & 0.658 & 0.419 & 0.008 & 1 & 2.242 & 0.138 & 0.024 \\
\hline & $\begin{array}{l}\text { Geometric } \\
\text { dominance }\end{array}$ & 1 & 2.312 & 0.132 & 0.026 & 1 & 4.818 & $0.031 *$ & 0.050 \\
\hline & $\begin{array}{l}\mathrm{PI}^{*} \text { Geometric } \\
\text { dominance }\end{array}$ & 1 & 0.304 & 0.583 & 0.003 & 1 & 0.273 & 0.603 & 0.003 \\
\hline
\end{tabular}


Table 4. Cont.

\begin{tabular}{|c|c|c|c|c|c|c|c|c|c|}
\hline & \multirow[b]{2}{*}{ Source } & \multicolumn{4}{|c|}{ Middle Cerebral Origin } & \multicolumn{4}{|c|}{ Middle Cerebral Distal Trunk } \\
\hline & & df & $\mathbf{F}$ & $p$ & $\eta p^{2}$ & df & $\mathrm{F}$ & $p$ & $\eta p^{2}$ \\
\hline \multirow[t]{3}{*}{ Q } & $\mathrm{Q}$ & 1 & 0.693 & 0.408 & 0.008 & 1 & 0.188 & 0.665 & 0.002 \\
\hline & $\begin{array}{l}\text { Geometric } \\
\text { dominance }\end{array}$ & 1 & 3.294 & 0.073 & 0.036 & 1 & 3.131 & 0.080 & 0.033 \\
\hline & $\begin{array}{l}\mathrm{Q}^{*} \text { Geometric } \\
\text { dominance }\end{array}$ & 1 & 84.636 & $0.000 *$ & 0.493 & 1 & 103.905 & $0.000 *$ & 0.533 \\
\hline \multirow[t]{3}{*}{ WSS $_{\text {SYS }}$} & $\mathrm{WSS}_{\mathrm{SYS}}$ & 1 & 0.939 & 0.335 & 0.011 & 1 & 1.303 & 0.257 & 0.014 \\
\hline & $\begin{array}{l}\text { Geometric } \\
\text { dominance }\end{array}$ & 1 & 1.492 & 0.225 & 0.017 & 1 & 0.005 & 0.945 & 0.000 \\
\hline & $\begin{array}{l}\text { WSS }_{S Y S}{ }^{*} \\
\text { Geometric } \\
\text { dominance }\end{array}$ & 1 & 33.575 & $0.000 *$ & 0.278 & 1 & 43.048 & $0.000 *$ & 0.321 \\
\hline \multirow[t]{3}{*}{ WSS $_{\text {DIAS }}$} & WSS $_{\text {DIAS }}$ & 1 & 0.001 & 0.976 & 0.000 & 1 & 0.046 & 0.861 & 0.001 \\
\hline & $\begin{array}{l}\text { Geometric } \\
\text { dominance }\end{array}$ & 1 & 0.109 & 0.742 & 0.001 & 1 & 1.367 & 0.245 & 0.015 \\
\hline & $\begin{array}{l}\text { WSS }_{\text {DIAS }} \\
\text { Geometric } \\
\text { dominance }\end{array}$ & 1 & 22.661 & 0.000 * & 0.207 & 1 & 27.122 & 0.000 * & 0.230 \\
\hline
\end{tabular}

Note. $p<0.05 ; \mathrm{PSV}=$ peak systolic velocity; $\mathrm{EDV}=$ end diastolic velocity; $\mathrm{VMEAN}=$ mean velocity; $\mathrm{RI}=$ resistance index; PI = pulsatility index; $\mathrm{Q}=$ blood flow volume; $\mathrm{WSS}_{\mathrm{SYS}}=$ systolic wall shear stress; WSSDIAS = diastolic wall shear stress; * significant $p$ values

Middle cerebral artery origin

A.
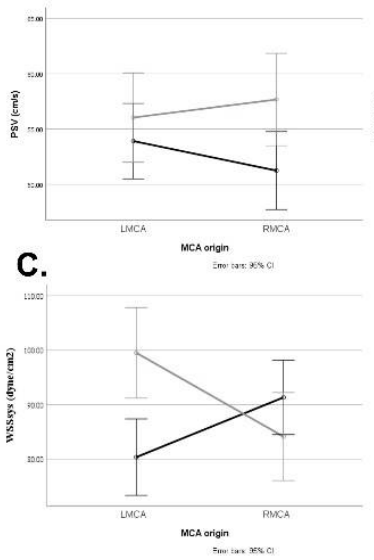

B.

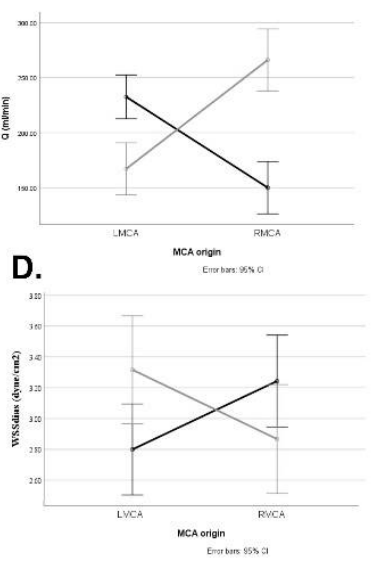

Middle cerebral distal trunk

E.

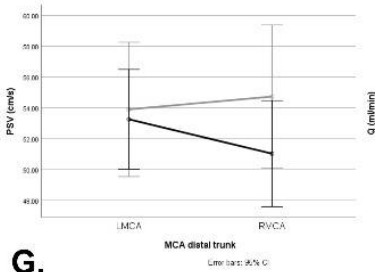

G.

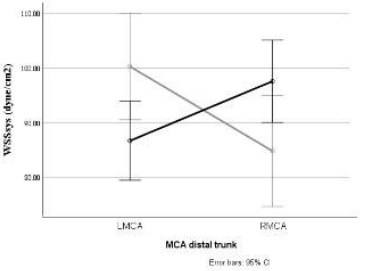

F.

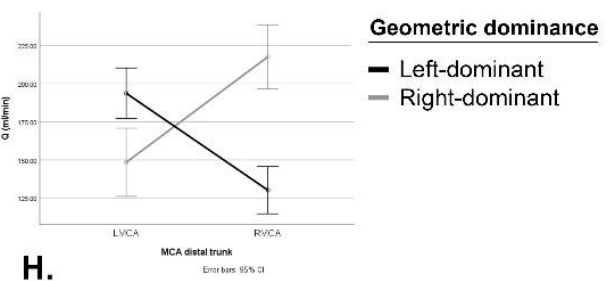

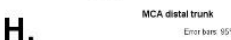

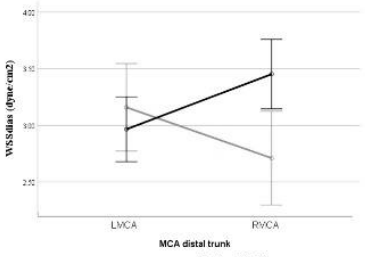

Figure 2. Interactions between haemodynamic and arterial wall shear stress variables and left versus right middle cerebral arteries at the origin (A-D) and distal trunk (E-H) in left and right dominant neonates. The haemodynamic variables are peak systolic volume $(\mathbf{A}, \mathbf{E})$ and blood flow volume $(\mathbf{B}, \mathbf{F})$. The shear stress variables are systolic wall shear stress $(\mathbf{C}, \mathbf{G})$ and diastolic wall shear stress $(\mathbf{D}, \mathbf{H})$. Abbreviations: LMCA = Left middle cerebral artery; RMCA = Right middle cerebral artery; PSV = Peak systolic velocity; $\mathrm{Q}=$ blood flow volume; WSSSYS = systolic wall shear stress; WSSDIAS = diastolic wall shear stress. Error bars show the $95 \%$ confidence interval.

The influence of the neonatal arterial geometry on the hemodynamics of these two sites varied, in that the effect of a structural dominance was more pervasive at the origin across most blood flow velocity and flow volume measures (Tables 3 and 4; Figure 2). More specifically, interactions were found in the peak systolic velocity, average velocity, and blood flow volume. Structural dominance of the distal middle cerebral trunk did not significantly influence the arterial velocity (peak systolic, end-diastolic, and mean velocities), but a significant influence of the geometry was seen in the blood flow volume. 
The resistance to the blood flow caused by the microvascular bed distal to the site of measurement did not significantly interact with the arterial geometry (Table 4). However, the main effect on the arterial resistance was found at the middle cerebral distal trunk, where the resistance distal to the middle cerebral artery trunk terminus was higher across both cerebral hemispheres in neonates with a rightward geometric dominance $(p=0.031)$. This main effect was also reflected in pulsatility indices.

No lateral differences in the arterial resistance were noted at the middle cerebral artery origin. A lateral difference in the arterial resistance was evident at the distal trunk, where neonates with a leftward structural dominance had a higher resistance and pulsatility index in the left cerebral hemisphere than they had in the right (Table 3). No left-right differences were found in those with a rightward arterial dominance.

\subsection{Shearing Stress Differences}

The neonatal arterial geometry differentially influenced peak systolic and end diastolic shearing forces at both arterial sites (Table 4; Figure 2). In participants with a leftward structural dominance, the peak systolic and end diastolic shear stresses were significantly higher on the right-side than on the left, and the converse was seen in right-dominant neonates.

\section{Discussion}

In adults, left-right asymmetries are normal attributes of cerebral perfusion, akin to well-established asymmetries in brain morphology [26,27]. Cerebral arterial diameters and blood flows have been investigated in neonates for a variety of largely clinical ends. Studies of diameters are restricted to autopsy series [28,29]. Blood flow velocity is commonly measured in vivo for routine clinical purposes [30-35].

To our knowledge, this is the first intentional investigation of structurofunctional neonatal cerebral arterial asymmetries in healthy term neonates at rest. Differences in diameter were found at each arterial site of interest, and the corresponding hemodynamics were biased towards larger arterial calibers. Leftward hemodynamic biases were found in neonates with larger arteries in the left cerebral hemisphere (left-dominant), while rightward hemodynamic biases were found in neonates with larger arteries in the right cerebral hemisphere (right-dominant). Very few neonates $(<8 \%)$ showed an absence of lateral differences in arterial diameter.

The pattern of asymmetry in middle cerebral Doppler waveforms differed between left- and right-dominant groups. Left-dominant neonates were typified by impressive differences in left-right peak systolic velocities that disappeared at the end systole. This peak systolic effect was absent bilaterally in neonates with larger arterial diameters on the right.

Although pulsatility and resistance indices are frequently used in clinical studies, the interpretation of these variables is dependent on several factors such as vascular resistance, arterial compliance, and the driving force of the arterial pulse wave [36]. Structural dominance did not play a role in resistance and pulsatility differences. Arterial pulsatility was not laterally biased in right-dominant neonates, but in left-dominant neonates pulsatility was left biased in the distal trunk of the middle cerebral artery. If one were to apply a traditional interpretation [37] to these findings, the degree of resistance in the cortical microvascular bed distal to the middle cerebral artery would be predicted to be higher in the left hemisphere of most neonates. Higher indices in the left middle cerebral artery would, in turn, indicate a decreased end-diastolic velocity, rendering the left hemisphere more prone to disorders such as stroke or venous infarcts, and left-biased resistance and pulsatility asymmetries in neonates have been documented previously [38].

The arterial endothelial wall shear stress exerts a key influence on the genesis of vascular pathology [39], in that a high shear stress has a protective effect on the endothelium [40]. The pathogenesis of the higher left-than-right incidence of cerebrovascular pathology in adults [41,42] and neonates [43] has been elusive, but clarification might be gained from the overall blood flow and wall shear stress asymmetries reported here. 
The present findings show that a systematic leftward arterial bias in wall shear stress is detectible in healthy term neonates. Shearing asymmetries systematically disadvantaged the left hemispheric endothelium with lower left-than-right peak systolic and end-diastolic endothelial shearing forces in neonates with larger left-sided arteries. The converse was seen in right-dominant neonates. This asymmetry therefore increased the neurovascular vulnerability in the left cerebral hemisphere of most healthy term neonates.

The findings of this study are consistent with the hypothesis that the wall shear stress varies according to geometric and behavioral lateralization in the neonatal cerebral arterial trunk. This adds to literature [44] demonstrating that the wall shear stress varies with location across the cardiovascular system. These findings therefore bring Murray's law of constant shearing forces throughout the arterial system [45] into question.

The ontogenesis of atherosclerosis begins very early in life. While incipient atherosclerotic changes are minor in most cases, the process can be accelerated in the presence of a variety of conditions [46]. Menshawi and colleagues [47] postulated that individuals born with an unfavorable arterial geometry are more susceptible to the atherosclerotic effects of traditional vascular risk factors. Although left-lateralized lesions are not inevitable, the predisposing effects of "atherosclerosis-enabling" anatomy reported here might provide the framework for a greater left-than-right incidence of cerebrovascular pathology.

If the present findings are stable across the lifespan and are also consistently discernible in adults, extended exposure to a lateralized arterial vulnerability might also shed light on the ontogenesis of leftward biases in the carotid intima-media wall thickness [48]; plaque incidence, thickness, and instability, as well as large-vessel ischemic events in adults [3].

There are documented associations between handedness and the left arterial intimal wall thickness of the carotids [49], as well as left-handedness and a lower risk of sudden death from brain infarction (typically associated with left-hemispheric stroke [50]. In an adult study, some of the present authors showed that the arterial length, diameter, resistance to blood flow, velocity, and volume flow rate are asymmetric and are intimately related to hand preference and proficiency, raising the possibility that these structurofunctional asymmetries arose in adaptation to greater metabolic demands in the dominant hemisphere in anticipation of the emergence of lateralized cognitive and behavioral functions [51].

Our data show that the asymmetric vascular ground plan found in adults is present in neonates. Ultimately, routine investigations of the neonatal brain should proceed on the expectation that asymmetries in the middle cerebral arteries are a normal attribute of the lateral cortical supply. Ironically, the lateralized neurovascular framework within which language develops might also contain the seeds of its most significant cerebrovascular threat.

Author Contributions: Conceptualization, A.J.v.V., M.S. (Michael Saling) and M.S. (Mark Solms); methodology, A.J.v.V. and S.R.; software, A.J.v.V. and S.R.; validation, S.R.; formal analysis, A.J.v.V.; investigation, A.J.v.V.; resources, S.R. and J.C.; data curation, A.J.v.V.; writing-original draft preparation, A.J.v.V. and M.S. (Michael Saling); writing—review and editing, A.J.v.V., M.S. (Michael Saling), P.A., S.R., M.S. (Mark Solms) and J.C.; visualization, A.J.v.V.; supervision, M.S. (Michael Saling); project administration, A.J.v.V.; funding acquisition, M.S. (Mark Solms). All authors have read and agreed to the published version of the manuscript.

Funding: This research received no external funding.

Institutional Review Board Statement: Royal Women's Hospital Human Research Ethics Committee Project 16/18 - Cerebral arterial asymmetries in the neonates.

Informed Consent Statement: Informed consent was obtained from the parents or legal guardians of all neonates involved in the study.

Data Availability Statement: The data presented in this study are available on request from the corresponding author. The data are not publicly available due to privacy reasons.

Acknowledgments: We are indebted the Royal Women's Hospital and Frances Perry House for providing the platform for us to conduct our study. We would also like to thank Julie Archbold for 
her help in calibrating the Doppler ultrasound machine. The financial assistance of the University of Melbourne is acknowledged.

Conflicts of Interest: The authors declare no conflict of interest.

\section{References}

1. Foerch, C.; Misselwitz, B.; Sitzer, M.; Berger, K.; Steinmetz, H.; Neumann-Haefelin, T. Difference in recognition of right and left hemispheric stroke. Lancet 2005, 366, 392-393. [CrossRef]

2. Hedna, V.S.; Bodhit, A.N.; Ansari, S.; Falchook, A.D.; Stead, L.; Heilman, K.M.; Waters, M.F. Hemispheric Differences in Ischemic Stroke: Is Left-Hemisphere Stroke More Common? J. Clin. Neurol. 2013, 9, 97-102. [CrossRef] [PubMed]

3. Selwaness, M.; van den Bouwhuijsen, Q.; van Onkelen, R.S.; Hofman, A.; Franco, O.; van der Lugt, A.; Wentzel, J.J.; Vernooij, M. Atherosclerotic plaque in the left carotid artery is more vulnerable than in the right. Stroke 2014, 45, 3226-3230. [CrossRef] [PubMed]

4. Denarié, N.; Gariepy, J.; Chironi, G.; Massonneau, M.; Laskri, F.; Salomon, J.; Levenson, J.; Simon, A. Distribution of ultrasonographically-assessed dimensions of common carotid arteries in healthy adults of both sexes. Atherosclerosis 2000, 148, 297-302. [CrossRef]

5. Cagnie, B.; Petrovic, M.; Voet, D.; Barbaix, E.; Cambier, D. Vertebral artery dominance and hand preference: Is there a correlation? Man. Ther. 2006, 11, 153-156. [CrossRef] [PubMed]

6. Luo, X.; Yang, Y.; Cao, T.; Li, Z. Differences in left and right carotid intima-media thickness and the associated risk factors. Clin. Radiol. 2011, 66, 393-398. [CrossRef]

7. Lin, P.-Y.; Roche-Labarbe, N.; Dehaes, M.; Fenoglio, A.; Grant, P.E.; Franceschini, M.A. Regional and Hemispheric Asymmetries of Cerebral Hemodynamic and Oxygen Metabolism in Newborns. Cereb. Cortex 2012, 23, 339-348. [CrossRef]

8. Zhao, M.; Amin-Hanjani, S.; Ruland, S.; Curcio, A.; Ostergren, L.; Charbel, F. Regional Cerebral Blood Flow Using Quantitative MR Angiography. Am. J. Neuroradiol. 2007, 28, 1470-1473. [CrossRef]

9. Kamath, S. Observations on the length and diameter of vessels forming the circle of Willis. J. Anat. 1981, 133, 419-423.

10. Baldassarre, D.; Amato, M.; Bondioli, A.; Sirtori, C.R.; Tremoli, E. Carotid artery intima-media thickness measured by ultrasonography in normal clinical practice correlates well with atherosclerosis risk factors. Stroke 2000, 31, 2426-2430. [CrossRef]

11. Herisson, F.; Heymann, M.-F.; Chétiveaux, M.; Charrier, C.; Battaglia, S.; Pilet, P.; Rouillon, T.; Krempf, M.; Lemarchand, P.; Heymann, D.; et al. Carotid and femoral atherosclerotic plaques show different morphology. Atherosclerosis 2011, 216, 348-354. [CrossRef] [PubMed]

12. Oxenham, H.; Sharpe, N. Cardiovascular aging and heart failure. Eur. J. Hear. Fail. 2003, 5, 427-434. [CrossRef]

13. Guzzetta, F.; Shackelford, G.D.; Volpe, S.; Perlman, J.M.; Volpe, J.J. Periventricular intraparenchymal endodensities in the premature newborn: Critical determinant of neurological outcome. Pediatrics 1986, 78, 995-1006. [CrossRef] [PubMed]

14. Perlman, J.M.; Rollins, N.K.; Evans, D. Neonatal stroke: Clinical characteristics and cerebral blood flow velocity measurements. Pediatr. Neurol. 1994, 11, 281-284. [CrossRef]

15. Uvebrant, P. Hemiplegic cerebral palsy. Aetiology and outcome. Acta Paediatr. Scand. Suppl. 1988, 345, 1-100. [CrossRef]

16. Miller, V. Neonatal cerebral infarction. Semin. Pediatr. Neurol. 2000, 7, 278-288. [CrossRef]

17. Coker, S.B.; Beltran, R.S.; Myers, T.F.; Hmura, L. Neonatal stroke: Description of patients and investigation into pathogenesis. Pediatr. Neurol. 1988, 4, 219-223. [CrossRef]

18. Dahl, A.; Russell, D.; Nyberg-Hansen, R.; Rootwelt, K. A Comparison of Regional Cerebral Blood Flow and Middle Cerebral Artery Blood Flow Velocities: Simultaneous Measurements in Healthy Subjects. J. Cereb. Blood Flow Metab. 1992, 12, 1049-1054. [CrossRef]

19. Oktar, S.; Yücel, C.; Karaosmanoglu, D.; Akkan, K.; Ozdemir, H.; Tokgoz, N.; Tali, T. Blood-Flow Volume Quantification in Internal Carotid and Vertebral Arteries: Comparison of 3 Different Ultrasound Techniques with Phase-Contrast MR Imaging. Am. J. Neuroradiol. 2006, 27, 363-369.

20. Hayashi, T.; Ichiyama, T.; Uchida, M.; Tashiro, N.; Tanaka, H. Evaluation by color Doppler and pulsed Doppler sonography of blood-flow velocities in intracranial-arteries during the early neonatal-period. Eur. J. Pediatr. 1922, 151, 461-465. [CrossRef]

21. Anwarm, M.A.; Bignall, W.; River, R.P.A. The variation with gestational age of the rheological properties of the blood of the new-born. Brit. J. Haematol. 1994, 86, 163-168. [CrossRef]

22. Wu, Y.-C.; Hsieh, W.-S.; Hsu, C.-H.; Chiu, N.-C.; Chou, H.-C.; Chen, C.-Y.; Peng, S.-F.; Hung, H.-Y.; Chang, J.-H.; Chen, W.J.; et al. Relationship of Neonatal Cerebral Blood Flow Velocity Asymmetry with Early Motor, Cognitive and Language Development in Term Infants. Ultrasound Med. Biol. 2013, 39, 797-803. [CrossRef] [PubMed]

23. Jahromi, A.S.; Cinà, C.S.; Liu, Y.; Clase, C.M. Sensitivity and specificity of color duplex ultrasound measurement in the estimation of internal carotid artery stenosis: A systematic review and meta-analysis. J. Vasc. Surg. 2005, 41, 962-972. [CrossRef] [PubMed]

24. Bishop, C.C.; Powell, S.; Rutt, D.; Browse, N.L. Transcranial Doppler measurement of middle cerebral artery blood flow velocity: A validation study. Stroke 1986, 17, 913-915. [CrossRef]

25. Kamouchi, M.; Kishikawa, K.; Okada, Y.; Inoue, T.; Ibayashi, S.; Iida, M. Reappraisal of Flow Velocity Ratio in Common Carotid Artery to Predict Hemodynamic Change in Carotid Stenosis. Am. J. Neuroradiol. 2005, 26, 957-962. [PubMed] 
26. Leutin, V.P.; Pystina, E.A.; Yarosh, S.V. Linear Blood Velocity in Arteries of the Brain Hemispheres in Left-Handers and RightHanders during Hypoxia. Hum. Physiol. 2004, 30, 290-292. [CrossRef]

27. Willis, M.W.; Ketter, T.A.; Kimbrell, T.A.; George, M.S.; Herscovitch, P.; Danielson, A.L.; Benson, B.E.; Post, R.M. Age, sex and laterality effects on cerebral glucose metabolism in healthy adults. Psychiatry Res. Neuroimaging 2002, 114, 23-37. [CrossRef]

28. Gielecki, J.; Zurada, A.; Kozlowska, H.; Nowak, D.; Loukas, M. Morphometric and volumetric analysis of middle cerebral artery in human fetus. Acta Neurobiol. Exp. 2009, 69, 129-137.

29. Seydel, H.G. The diameters of cerebral arteries of the human fetus. Anat. Rec. 1964, 150, 79-88. [CrossRef]

30. Ebbing, C.; Rasmussen, S.; Kiserud, T. Middle cerebral artery blood flow velocities and pulsatility index and the cerebroplacental pulsatility ratio: Longitudinal reference ranges and terms for serial measurements. Ultrasound Obstet. Gynecol. 2007, 30, 287-296. [CrossRef]

31. Kehrer, M.; Krägeloh-Mann, I.; Goelz, R.; Schöning, M. The Development of Cerebral Perfusion in Healthy Preterm and Term Neonates. Neuropediatrics 2003, 34, 281-286. [CrossRef]

32. Pezzati, M.; Dani, C.; Biadaioli, R.; Filippi, L.; Biagiotti, R.; Giani, T.; Rubaltelli, F.F. Early postnatal Doppler assessment of cerebral blood flow velocity in healthy preterm and term infants. Dev. Med. Child Neurol. 2002, 44, 745-752. [CrossRef]

33. Seffah, J.D.; Swarray-Deen, A. Fetal middle cerebral artery Doppler indices and clinical application at Korle Bu Teaching Hospital, Accra, Ghana. Int. J. Gynecol. Obstet. 2016, 134, 135-139. [CrossRef]

34. Sinha, A.K.; Cane, C.; Kempley, S.T. Blood flow in the common carotid artery in term and preterm infants: Reproducibility and relation to cardiac output. Arch. Dis. Child.-Fetal Neonatal Ed. 2005, 91, F31-F35. [CrossRef]

35. Yoshida, H.; Yasuhara, A.; Kobayashi, Y. Transcranial Doppler sonographic studies of cerebral blood flow velocity in neonates. Pediatr. Neurol. 1991, 7, 105-110. [CrossRef]

36. Bude, R.O.; Rubin, J.M. Relationship between the Resistive Index and Vascular Compliance and Resistance. Radiology 1999, 211, 411-417. [CrossRef]

37. de Riva, N.; Budohoski, K.P.; Smielewski, P.; Kasprowicz, M.; Zweifel, C.; Steiner, L.A.; Reinhard, M.; Fábregas, N.; Pickard, J.D.; Czosnyka, M. Transcranial Doppler pulsatility index: What it is and what it isn't. Neurocrit. Care 2012, 17, 58-66. [CrossRef]

38. Ecury-Goossen, G.M.; Raets, M.M.A.; Camfferman, F.A.; Vos, R.H.J.; Van Rosmalen, J.; Reiss, I.K.M.; Govaert, P.; Dudink, J. Resistive indices of cerebral arteries in very preterm infants: Values throughout stay in the neonatal intensive care unit and impact of patent ductus arteriosus. Pediatr. Radiol. 2016, 46, 1291-1300. [CrossRef]

39. Davies, P.F. Hemodynamic shear stress and the endothelium in cardiovascular pathophysiology. Nat. Clin. Pr. Cardiovasc. Med. 2009, 6, 16-26. [CrossRef]

40. Slager, C.J.; Wentzel, J.J.; Gijsen, F.J.H.; Schuurbiers, J.C.H.; van der Wal, A.; Van Der Steen, A.F.W.; Serruys, P.W. The role of shear stress in the generation of rupture-prone vulnerable plaques. Nat. Clin. Pr. Cardiovasc. Med. 2005, 2, 401-407. [CrossRef]

41. Naess, H.; Waje-Andreassen, U.; Thomassen, L.; Myhr, K.M. High incidence of left cerebral infarction among young adults. J. Stroke Cerebrovasc Dis. 2006, 15, 241-244. [CrossRef]

42. Rodríguez Hernández, S.A.; Kroon, A.A.; van Boxtel, M.P.; Mess, W.H.; Lodder, J.; Jolles, J.; de Leeuw, P.W. Is there a side predilection for cerebrovascular disease? Hypertension 2003, 42, 56-60. [CrossRef]

43. Lee, J.; Croen, L.A.; Backstrand, K.H.; Yoshida, C.K.; Henning, L.H.; Lindan, C.; Ferriero, D.M.; Fullerton, H.J.; Barkovich, A.J.; Wu, Y.W. Maternal and infant characteristics associated with perinatal arterial stroke in the infant. JAMA 2005, 293, 723-729. [CrossRef]

44. Dammers, R.; Stifft, F.; Tordoir, J.H.M.; Hameleers, J.M.M.; Hoeks, A.P.G.; Kitslaar, P.J.E.H.M. Shear stress depends on vascular territory: Comparison between common carotid and brachial artery. J. Appl. Physiol. 2003, 94, 485-489. [CrossRef]

45. Murray, C.D. The Physiological Principle of Minimum Work: I. The Vascular System and the Cost of Blood Volume. Proc. Natl. Acad. Sci. USA 1926, 12, 207-214. [CrossRef]

46. Hong, Y.M. Atherosclerotic Cardiovascular Disease Beginning in Childhood. Korean Circ. J. 2010, 40, 1-9. [CrossRef]

47. Menshawy, K.; Mohr, J.P.; Gutierrez, J.G.A. A Functional Perspective on the Embryology and Anatomy of the Cerebral Blood Supply. J. Stroke 2015, 17, 144-158. [CrossRef]

48. Lemme, C.; Jogestrand, T.; de Faire, U. Carotid intima-media thickness and plaque in borderline hypertension. Stroke 1995, $26,34-39$.

49. Önbaş, O.; Dane, Ş.; Kantarci, M.; Koplay, M.; Alper, F.; Okur, A. Clinical importance of asymmetry and handedness differences in common carotid artery intima-media thickness. Int. J. Neurosci. 2007, 117, 433-441. [CrossRef]

50. Algra, A.; Gates, P.C.; Fox, A.J.; Hachinski, V.; Barnett, H.J. North American Symptomatic Carotid Endarterectomy Trial Group: Side of brain infarction and long-term risk of sudden death in patients with symptomatic carotid disease. Stroke 2003, 34, 2871-2875. [CrossRef]

51. Jansen van Vuuren, A.; Saling, M.M.; Ameen, O.; Naidoo, N.; Solms, M. Hand preference is selectively related to common and internal carotid arterial asymmetry. Laterality 2016, 4, 377-398. [CrossRef] 